\title{
Parent-reported feeding and swallowing difficulties of children with Autism Spectrum Disorders (aged 3 to 5 years) compared to typically developing peers: a South African study
}

\author{
Mari Viviers ${ }^{1,2}$, Marguerite Jongh ${ }^{2}$, Lindsay Dickonson ${ }^{1}$, Roxanne Malan ${ }^{1}$, Tamaryn Pike $^{1}$
}

1. University of Pretoria, Speech-language therapy and Audiology.

2. Sefako Makgatho Health Sciences University, Speech-language pathology and Audiology.

\begin{abstract}
Background: Research on aspects of neurodevelopment such as feeding and swallowing difficulties in children with Autism Spectrum Disorders (ASD) is limited in low and middle income countries such as South Africa.

Method: A descriptive comparative group design was used to investigate feeding and swallowing difficulties of young children with ASD in comparison to typically developing peers. The Brief Autism Mealtime Behavioural Inventory (BAMBI) was used.

Results: Findings indicated a significant difference in the severity of feeding and swallowing difficulties between the two groups. Difficulties such as food selectivity, sensory processing difficulties, oral-motor difficulties and symptoms of dysphagia were identified. The findings added to the existing global literature on feeding and swallowing difficulties in young children with ASD but provide a unique first perspective on these difficulties in South African children with ASD.

Conclusion: Findings also highlighted the use of the BAMBI as an adjunct clinical tool to encourage comprehensive parental report during feeding assessment in this population. Cultural adaptation of the BAMBI for future use in African countries should be considered. A better local understanding of the parental perspective on the multidimensional nature of the feeding and swallowing difficulties displayed by young children with ASD was obtained.
\end{abstract}

Keywords: Parent-reported feeding, swallowing difficulties, Autism Spectrum Disorders, South Africa.

DOI: https://dx.doi.org/10.4314/ahs.v20i1.59

Cite as: Viviers M, Jongh M, Dickonson L, Malan R, Pike T. Parent-reported feeding and swallowing difficulties of children with Autism Spectrum Disorders (aged 3 to 5 years) compared to typically developing peers: a South African study. Afri Health Sci. 2020;20(1):524-32. bttps:/ / dx.doi.org/ 10.4314/abs.v20i1.59

\section{Introduction}

Autism spectrum disorders (ASD) represent a range of complex neurodevelopmental disorders varying in severity that are characterized by a cluster of symptoms, including impairments in social interaction, communication, sensory integration difficulties and behaviour ${ }^{1,2,3}$. Individuals with ASD demonstrate restricted, repetitive and stereotypical interests, activities and behaviours. Global research indicates that the disorder is typically first diagnosed in infancy and early childhood (as young as 18 months), and usually emerges before the age of three ${ }^{1,2}$. Most research about ASD stems from high-income coun-

\section{Corresponding author: \\ Mari Viviers, \\ University of Pretoria, \\ Speech-language therapy and Audiology \\ Email: marimviviers@gmail.com, \\ mmdebeer@hotmail.com}

tries, but there have been quite a few studies in Africa, particularly in South Africa and Nigeria.

One such study by De Vries ${ }^{4}$ indicated that parents only became concerned for their child's behaviour at 22.5 months and that the diagnosis of ASD was on average made at 44.7 months. De Vries ${ }^{4}$ also states that a lack of research funding impacts on the development of assessment policies and guidelines in most African countries. As limited as diagnostic resources and interventions are in South Africa, they are far more abundant than in other African countries. As a result little is known about ASD and neuro-development, such as specific feeding behaviours and swallowing difficulties of children with $\mathrm{ASD}^{5}$, in low-and middle income countries. A dearth of research remains globally and in the African context on feeding difficulties in $\mathrm{ASD}^{6,7}$.

Behavioural feeding difficulties and atypical eating is pervasive among children with ASD with prevalence as high 
as $46-89 \% 0^{6,7}$. Such difficulties may pose a significant challenge during family mealtimes creating tense interactions between family members and increasing the burden of stress $^{6}$. Limitations in previous global research studies include a dearth of research on feeding difficulties in ASD, restricted generalizability of findings due to small sample sizes as well as insufficient knowledge of comorbid medical conditions, such as eosinophilic esophagitis $(\mathrm{EE})^{5}$. EE has an impact on the gut microbiome in children with ASD, which ultimately may have a greater impact on feeding than ASD itself ${ }^{5}$. An insufficient understanding of how the feeding behaviours of children with autism compare to the feeding behaviours of children without autism is an additional limitation ${ }^{5}$. Martins and colleagues ${ }^{8}$ noted that parents of children with ASD perceived a higher incidence of feeding difficulties compared to parents of typically developing children. These researchers thus encouraged the comparison of eating behaviour of children with ASD and typically developing (TD) children, since $25-45 \%$ of TD children also exhibit eating and feeding difficulties ${ }^{8}$.

The feeding problems associated with ASD include food selectivity, picky eating, oral-motor difficulties, obsessive eating patterns, inappropriate eating rate, food cravings, pica, restricted use of utensils and specific food presentation $^{6,9,10}$. Dysphagia may also be common in children with ASD, although more definitive information is needed regarding its manifestation in this population?. Secondary problems may include nutritional deficiencies, increased risk for illness, aspiration pneumonia, dehydration, airway obstruction, weight loss or obesity and significant health problems such as rickets with adverse effects on the quality of life $\mathrm{e}^{11,12,13}$.

From the preceding literature it is apparent that a dearth of studies on feeding and swallowing difficulties in young children with ASD exists in South Africa. Globally as well as in the multiracial and multicultural South African context, the need for further research on this topic was identified. The aforementioned consequences of feeding and swallowing problems, such as negative health sequalae and challenges in the home and social environments created added impetus for further research. One such a need was to investigate parental perception on feeding and swallowing difficulties in young children with ASD in comparison to their typically developing peers and it is likely the first study of its kind in the South African context.

\section{Method}

Ethical clearance was obtained from the Research Ethics Committee at the University of Pretoria, South Africa.

\section{Research design}

A descriptive static-group comparison design ${ }^{14}$ was used to investigate the feeding and swallowing difficulties of 3:0 to 5:11 year old children with ASD in comparison with typically developing peers.

\section{Participants and sampling}

The group of children with ASD included 21 parents of children from varying cultural groupings in Gauteng, South Africa (aged 3:0 to 5:11 years) with a confirmed diagnosis of ASD. The TD group included 21 parents of typically developing peers (in the stated age range). The inclusion criteria for selecting this age range was due to the diagnosis and diagnostic application measures of ASD in children under the age of three years not being well established ${ }^{1,15}$. ASD diagnostic status was confirmed by each child's treating physician or medical team.

Purposive sampling was used ${ }^{16}$. Telephone and e-mail contact were made with relevant societies representing children with ASD and preschools to access TD children, as well as the parents to be included in the study. A document including information regarding the study was firstly sent to the various societies/preschools via e-mail in order to obtain permission to contact the parents involved in each institution. Thereafter, an information brochure was sent to parents via e-mail, requesting their participation in the study. The purpose of the study was explained to both the societies/preschools and the parents. Lists of the parents' e-mail addresses were obtained from the various societies/preschools. Once these were obtained, it was possible for the researchers to send online informed consent documents and questionnaires to every parent on the list. It was necessary for the researchers to include contact information, information on the study and their credentials in the informed consent forms as this creates opportunities for e-mail interaction between researchers and participants.

The demographic information and characteristics for the two groups are presented in Table 1 and Table 2. 
Table 1: Participant description typically developing children $(n=21)$

\begin{tabular}{|c|c|c|c|}
\hline \multicolumn{2}{|c|}{ Participant characteristics } & Frequency & $\%$ \\
\hline \multirow[t]{4}{*}{ Age } & $3: 0-3: 11$ & 8 & 38 \\
\hline & $4: 0-4: 11$ & 8 & 38 \\
\hline & $5: 0-5: 11$ & 3 & 14 \\
\hline & Not indicated* & 2 & 10 \\
\hline \multirow[t]{2}{*}{ Gender } & Male & 10 & 48 \\
\hline & Female & 11 & 52 \\
\hline $\begin{array}{l}\text { Other medical } \\
\text { conditions }\end{array}$ & None reported $* *$ & 20 & 95 \\
\hline \multirow{3}{*}{$\begin{array}{l}\text { Parental level of } \\
\text { education }\end{array}$} & Matric & 2 & 10 \\
\hline & Diploma/Degree & 14 & 66 \\
\hline & $\begin{array}{l}\text { Post-graduate } \\
\text { qualification }\end{array}$ & 5 & 24 \\
\hline \multirow{3}{*}{$\begin{array}{l}\text { Parental } \\
\text { employment } \\
\text { status }\end{array}$} & Employed & 12 & 57 \\
\hline & Unemployed & 1 & 5 \\
\hline & $\begin{array}{c}\text { Full time caregiver, } \\
\text { i.e. stay-at-home } \\
\text { parent }\end{array}$ & 8 & 38 \\
\hline \multirow{7}{*}{$\begin{array}{l}\text { Average monthly } \\
\text { family income }\end{array}$} & $<Z A R 5000$ & 1 & 5 \\
\hline & ZAR5000-10000 & 0 & 0 \\
\hline & ZAR10 000-15000 & 3 & 14 \\
\hline & ZAR15 000-20000 & 1 & 5 \\
\hline & ZAR20 000-25000 & 3 & 14 \\
\hline & $>Z A R 25000$ & 12 & 57 \\
\hline & Not indicated & 1 & 5 \\
\hline \multirow{7}{*}{$\begin{array}{l}\text { Cultural } \\
\text { grouping/s of } \\
\text { family }\end{array}$} & Northern Sotho & 1 & 5 \\
\hline & Southern Sotho & 1 & 5 \\
\hline & English & 10 & 48 \\
\hline & Afrikaans & 4 & 19 \\
\hline & Swati & 1 & 5 \\
\hline & English \& Afrikaans & 3 & 14 \\
\hline & Xhosa \& Zulu & 1 & 5 \\
\hline \multirow[t]{4}{*}{ Province } & Gauteng & 12 & 57 \\
\hline & Mpumalanga & 5 & 24 \\
\hline & North West & 2 & 10 \\
\hline & Eastern Cape & 1 & 5 \\
\hline
\end{tabular}


Table 2 Participant description children with ASD ( $\mathrm{n}=21)$

\begin{tabular}{|c|c|c|c|}
\hline \multicolumn{2}{|c|}{ Participant characteristics } & \multirow{2}{*}{$\begin{array}{r}\text { Frequency } \\
9\end{array}$} & \multirow{2}{*}{$\begin{array}{c}\% \\
43 \\
\end{array}$} \\
\hline Age & $3: 0-3: 11$ & & \\
\hline & $4: 0-4: 11$ & 6 & 27 \\
\hline & $5: 0-5: 11$ & 5 & 24 \\
\hline & Not indicated* & 1 & 5 \\
\hline \multirow[t]{2}{*}{ Gender } & Male & 16 & 76 \\
\hline & Female & 5 & 24 \\
\hline \multirow[t]{3}{*}{$\begin{array}{l}\text { Diagnosis of ASD } \\
\text { made by... }\end{array}$} & $\begin{array}{c}\text { Paediatric neurologist/ } \\
\text { Developmental paediatrician }\end{array}$ & 15 & 71 \\
\hline & Psychiatrist & 1 & 5 \\
\hline & Team $^{* *}$ & 5 & 24 \\
\hline \multirow{6}{*}{$\begin{array}{l}\text { Other medical } \\
\text { conditions }\end{array}$} & None & 16 & 75 \\
\hline & Eczema & 1 & 5 \\
\hline & Neurofibromatosis & 1 & 5 \\
\hline & Heart conditions & 1 & 5 \\
\hline & Food allergies/intolerances & 1 & 5 \\
\hline & Ear infections & 1 & 5 \\
\hline \multirow{4}{*}{$\begin{array}{l}\text { Parental level of } \\
\text { education }\end{array}$} & Grade 10 & 1 & 5 \\
\hline & Matric & 9 & 43 \\
\hline & Diploma/Degree & 6 & 29 \\
\hline & Post-graduate qualification & 4 & 19 \\
\hline \multirow{4}{*}{$\begin{array}{l}\text { Parental employment } \\
\text { status }\end{array}$} & Employed & 9 & 43 \\
\hline & Unemployed & 4 & 19 \\
\hline & Full time caregiver, i.e. stay-at-home parent & 7 & 33 \\
\hline & Not indicated & 1 & 5 \\
\hline \multirow{7}{*}{$\begin{array}{l}\text { Average monthly } \\
\text { family income }\end{array}$} & $<$ ZAR5000 & 6 & 29 \\
\hline & ZAR5000-10000 & 0 & 0 \\
\hline & ZAR10 000-15000 & 0 & 0 \\
\hline & ZAR15 000-20000 & 5 & 24 \\
\hline & ZAR20 000-25000 & 3 & 14 \\
\hline & $>$ ZAR25000 & 3 & 14 \\
\hline & Not indicated & 4 & 19 \\
\hline \multirow{8}{*}{$\begin{array}{l}\text { Cultural grouping/s } \\
\text { of family }\end{array}$} & Zulu & 4 & 19 \\
\hline & Northern Sotho & 2 & 10 \\
\hline & Southern Sotho & 5 & 24 \\
\hline & English & 1 & 5 \\
\hline & Afrikaans & 5 & 24 \\
\hline & German \& English & 1 & 5 \\
\hline & English \& Afrikaans & 2 & 10 \\
\hline & Southern Sotho \& Afrikaans & 1 & 5 \\
\hline \multirow[t]{3}{*}{ Province } & Gauteng & 12 & 57 \\
\hline & Mpumalanga & 4 & 19 \\
\hline & Free State & 5 & 24 \\
\hline \multirow{3}{*}{$\begin{array}{l}\text { Demographic } \\
\text { distribution }\end{array}$} & Rural & 1 & 5 \\
\hline & Semi-rural & 4 & 19 \\
\hline & Urban & 16 & 76 \\
\hline
\end{tabular}

The characteristics of the children with ASD and the TD peers in terms of age and gender were mostly similar. Conversely, the males with ASD far outweighed the female cohort (16:5). Having more males present with ASD in a study is fairly common. However, the parental information for the two groups presented with some disparities regarding their education level, employment status and average monthly income as well as demographic distribution. The majority of parents $(66 \%)$ from the TD group had either a diploma or degree with only one of the parents being unemployed, whereas $29 \%$ of the parents from the ASD group had a diploma or degree and 4 parents $(19 \%)$ were unemployed. This correlated with the monthly income of the parents as the group of parents from the TD group had a higher monthly income. Furthermore the demographic distribution was different as $76 \%$ of the group of ASD participants resided in urban areas whereas $95 \%$ of the TD group did. 


\section{Variables}

Categorical variables such as age, gender and diagnostic status were included to ensure that the experimental and control groups came from similar backgrounds as to eliminate confounding variables. The quantitative variables that were examined in the $\mathrm{BAMBI}^{17}$ were measured on a Likert scale to obtain numerical data that fell on a continuum. As the BAMBI questionnaire was developed from a psychological and behavioural perspective, the current study described the variables categorically (without changing the content of the BAMBI) to comprehensively investigate the feeding and swallowing difficulties in children with ASD. Hence, categorical variables measured with the BAMBI included the presence of oral-motor difficulties; the presence of obsessive eating patterns; sensory processing difficulties; the requirement of specific utensils, food presentation and symptoms of dysphagia. The variables investigated are presented in Table 3.

Table 3 Variables measured by the BAMBI

\begin{tabular}{|c|c|c|}
\hline $\begin{array}{l}\text { Measured } \\
\text { variable }\end{array}$ & Questions on the BAMBI related to variable & Rationale for variable inclusion \\
\hline $\begin{array}{l}\text { Atypical feeding } \\
\text { behaviour }\end{array}$ & $\begin{array}{l}\text { Q1: My child cries or screams during mealtimes. } \\
\text { Q3: My child remains seated at the table until } \\
\text { his/her meal is finished. } \\
\text { Q5: My child is aggressive during mealtimes } \\
\text { (pushing/throwing utensils for food). } \\
\text { Q6: My child displays self-injurious behaviour } \\
\text { during mealtime (hitting self, biting self). } \\
\text { Q7: My child is disruptive during mealtimes } \\
\text { (pushing/throwing utensils for food). }\end{array}$ & $\begin{array}{l}\text { Children with ASD exhibit strong } \\
\text { behavioural responses when offered food } \\
\text { they do not wish to consume such } \\
\text { as getting up from their seats during a } \\
\text { meal and throwing food. These behaviours } \\
\text { are considered to be disruptive during } \\
\text { mealtimes. Self-injurious behaviour is also } \\
\text { characteristic of ASD. }\end{array}$ \\
\hline $\begin{array}{l}\text { Food selectivity } \\
\text { and preferences }\end{array}$ & $\begin{array}{l}\text { Q2: My child turns his/her head away from food. } \\
\text { Q8: My child closes his/her mouth tightly when } \\
\text { food is presented. } \\
\text { Q10: My child is willing to try new foods. } \\
\text { Q11: My child dislikes certain foods and won't } \\
\text { eat them. } \\
\text { Q13: My child prefers the same foods at every } \\
\text { meal. } \\
\text { Q15: My child accepts or prefers a variety of } \\
\text { foods. } \\
\text { Q17: My child prefers only sweet foods (sweets, } \\
\text { sugary cereal). } \\
\text { Q18: My child prefers to have foods prepared in a } \\
\text { particular way (for example, fried foods, cold } \\
\text { cereals, raw vegetables). }\end{array}$ & $\begin{array}{l}\text { Food selectivity encompass food refusal } \\
\text { and is manifested in behaviours such as } \\
\text { turning the head away and mouth closure } \\
\text { upon presentation of unwanted food. Picky } \\
\text { eating is indicated when a child refuses to } \\
\text { eat or even try a variety of foods or eats the } \\
\text { same foods at every meal. Picky eating is } \\
\text { linked to food selectivity. }\end{array}$ \\
\hline $\begin{array}{l}\text { Oral-motor } \\
\text { difficulties }\end{array}$ & $\begin{array}{l}\text { Q4: My child expels food that he/she has eaten. } \\
\text { Q12: My child refuses to eat certain foods that } \\
\text { require a lot of chewing }\end{array}$ & $\begin{array}{l}\text { Children may expel food as a result of oral- } \\
\text { motor difficulties. Chewing is one example } \\
\text { of a complex oral-motor skill that if not } \\
\text { adequately performed can contribute to } \\
\text { feeding problems. }\end{array}$ \\
\hline $\begin{array}{l}\text { Sensory } \\
\text { processing } \\
\text { difficulties }\end{array}$ & $\begin{array}{l}\text { Q4: My child expels food that he/she has eaten. } \\
\text { Q12: My child refuses to eat certain foods that } \\
\text { require a lot of chewing } \\
\text { Q14: My child prefers "crunchy" foods (for } \\
\text { example, snacks and crackers). } \\
\text { Q18: My child prefers to have foods prepared in a } \\
\text { particular way (for example, fried foods, cold } \\
\text { cereals, raw vegetables). }\end{array}$ & $\begin{array}{l}\text { Children with oral sensory difficulties may } \\
\text { have low registration of food in the mouth } \\
\text { and may expel it. The texture of food may } \\
\text { be rejected by children with ASD due to } \\
\text { sensory processing issues that may not } \\
\text { support chewing of food. Preferences } \\
\text { regarding textures of foods are linked to } \\
\text { sensory processing deficits. }\end{array}$ \\
\hline Dysphagia & $\begin{array}{l}\text { Q4: My child expels food that he/she has eaten. } \\
\text { Q12: My child refuses to eat certain foods that } \\
\text { require a lot of chewing }\end{array}$ & $\begin{array}{l}\text { Dysphagia can occur at various phases of } \\
\text { swallowing, and the oral phase involves } \\
\text { skills such as sucking and chewing. }\end{array}$ \\
\hline $\begin{array}{l}\text { Obsessive eating } \\
\text { patterns }\end{array}$ & $\begin{array}{l}\text { Q9: My child is flexible about mealtime routines } \\
\text { (for example, times for meals, seating } \\
\text { arrangements and place setting). } \\
\text { Q16: My child prefers to have food served in a } \\
\text { particular way. }\end{array}$ & $\begin{array}{l}\text { Obsessive eating patterns may be related to } \\
\text { the need for rigid routines in children with } \\
\text { ASD. }\end{array}$ \\
\hline $\begin{array}{l}\text { Requirement of } \\
\text { specific food } \\
\text { presentation and } \\
\text { utensils }\end{array}$ & $\begin{array}{l}\text { Q16: My child prefers to have food served in a } \\
\text { particular way. }\end{array}$ & $\begin{array}{l}\text { The need for specific food presentation and } \\
\text { use of familiar preferred utensils may also } \\
\text { be linked to the need for rigid routines in } \\
\text { children with ASD. }\end{array}$ \\
\hline
\end{tabular}




\section{Materials}

The validated Brief Autism Mealtime Behaviour Inventory (BAMBI) was selected for this study since it can be utilized by a variety of healthcare professionals ${ }^{17,18}$. The BAMBI questionnaire consists of questions that elicit information about the child's behaviour and skills during mealtimes as well as the child's food preferences and acceptance. This questionnaire was accompanied by a self-developed background questionnaire to obtain relevant information regarding the demographics, socio-economic status and biographical information of the participants and their children. In addition, general information regarding a history of feeding and swallowing difficulties experienced before the age of three years was obtained. The two questionnaires were electronically linked to improve user friendliness in the parental survey.

\section{Procedures}

An online survey was conducted over a two month period. The electronic questionnaire was sent via e-mail to the research participants in a programme entitled Google Docs. Data recording was done automatically in the programme and the findings of the questionnaires were stored in Microsoft Excel 2010 format.

\section{Data processing and analysis}

Parental responses were arranged on a Likert scale to convert parental reports of feeding and swallowing difficulties into quantitative data. To obtain an indication of the feeding and swallowing difficulties, the BAMBI questionnaire (questions 15 to 32) was analysed. To analyse the BAMBI questionnaire a total score of the feeding and swallowing difficulties for each child was derived, totalling the sum of the Likert responses - bearing in mind that questions 17, 23, 24 and 29 were reverse-scored.

For each question, the response indicating the most severe feeding/swallowing problem correlated with a score of 5 . The total score for questions 15 to 32 was calculated on Microsoft Excel 2010 which determined the general severity of the feeding and swallowing difficulties that were reported. The higher the value of the total score, the greater the severity of the feeding and/or swallowing difficulties experienced by the child. After calculating the total score for each participant the composite scores were obtained for eacvariable as they related to individual participants. This entailed summing responses for questions measuring specific variables to obtain a severity score for each variable as they related to each participant. Hence, the composite scores for each variable, as well as the total scores, were converted into percentages using STATA: Data Analysis and Statistical Software 28 Version 11. These percentages represented the fraction of severity which each participant experienced for each variable, with 100 percent representing the most severe difficulty.

The means, medians, standard deviations and ranges for the experimental and control groups were determined. Normally distributed variables were analysed with the t-test $(\mathrm{p}>0.05=$ statistical significance).

The Wilcoxon rank-sum test was used to determine whether the differences between the median values for each group were statistically significant, thus enabling comparison of the atypical feeding behaviours in children with ASD and TD peers. Furthermore oral-motor difficulties, obsessive eating patterns, sensory processing difficulties, requirement of specific utensils and food presentation and symptoms of dysphagia were compared.

\section{Reliability and Validity}

Satisfactory reliability and validity was present by using the validated BAMBI questionnaire ${ }^{17,18}$. The limitation of confounding variables facilitated external validity to the larger paediatric ASD and typically developing populations.

\section{Findings}

The parent reported feeding and swallowing difficulties of children with ASD were compared to those of TD peers by using the means, medians, standard deviations and ranges (minimum and maximum values) for the percentage scores of the variables under investigation. The findings are presented in Table 4. 
Table 4 Comparative data: Young children with ASD and TD peers

\begin{tabular}{|c|c|c|c|c|c|c|c|c|c|c|c|}
\hline \multirow[t]{2}{*}{ Variable } & \multicolumn{5}{|c|}{ Children with ASD $(n=21)$} & \multicolumn{5}{|c|}{ Typically developing peers $(\mathrm{n}=21)$} & \multirow[t]{2}{*}{ P-values* } \\
\hline & Mean & SD & Median & Min & Max & Mean & SD & Median & Min & Max & \\
\hline $\begin{array}{l}\text { Food } \\
\text { selectivity } \\
\text { and } \\
\text { preferences }\end{array}$ & 58 & 14 & 54 & 40 & 83 & 41 & 13 & 40 & 23 & 74 & 0.0002 \\
\hline $\begin{array}{l}\text { Atypical } \\
\text { feeding } \\
\text { behaviours }\end{array}$ & 44 & 17 & 40 & 24 & 84 & 28 & 6 & 28 & 20 & 36 & 0.0001 \\
\hline $\begin{array}{l}\text { Oral-motor } \\
\text { difficulties }\end{array}$ & 48 & 24 & 50 & 20 & 100 & 30 & 13 & 30 & 20 & 60 & 0.0144 \\
\hline $\begin{array}{l}\text { Sensory } \\
\text { processing } \\
\text { difficulties }\end{array}$ & 54 & 15 & 55 & 20 & 75 & 39 & 13 & 35 & 20 & 65 & 0.0011 \\
\hline $\begin{array}{l}\text { Obsessive } \\
\text { eating } \\
\text { patterns }\end{array}$ & 57 & 16 & 53 & 33 & 100 & 45 & 19 & 40 & 20 & 80 & 0.0226 \\
\hline $\begin{array}{l}\text { Specific } \\
\text { utensils and } \\
\text { food } \\
\text { presentation }\end{array}$ & 54 & 24 & 60 & 20 & 100 & 41 & 26 & 40 & 20 & 100 & 0.0529 \\
\hline Dysphagia & 48 & 24 & 50 & 20 & 100 & 30 & 13 & 30 & 20 & 60 & 0.0144 \\
\hline $\begin{array}{l}\text { TOTAL } \\
\text { SCORE } \\
\end{array}$ & 53 & 12 & 50 & 39 & 77 & 38 & 10 & 36 & 24 & 62 & \\
\hline
\end{tabular}

*Significance taken to be $p<0.05$ for comparative variables on the Rank-Sum Test

The mean percentage score for the severity of total feeding and swallowing difficulties in children with ASD differed significantly from that of TD children $(p=0.0000)$. This implies that the overall severity of feeding and swallowing difficulties differed between the two groups. The severity difference between the populations was statistically significant, with the ASD group scoring 15\% higher. The mean percentage score for the severity of food selectivity and preferences in children with ASD also differed significantly from that of TD children $(p=0.0002)$. The severity score in the ASD group was 17\% higher than the TD group.

The differences between the median percentage scores of severity for atypical feeding behaviours, oral-motor difficulties, obsessive eating patterns, sensory processing difficulties and dysphagia between the two groups indicated a statistically significant difference in terms of these variables. However, there was not a significant difference $(p=0.0529)$ with regard to the requirement of specific utensils and food presentation.

Participants in the group of children with ASD obtained higher median percentage scores for the severity of feeding and swallowing difficulties for all examined variables, resulting in more severe problems regarding atypical feeding behaviours, oral-motor difficulties, obsessive eating patterns, sensory processing difficulties and symptoms of dysphagia.

The greatest differences in severity were found regarding oral-motor difficulties, sensory processing difficulties and symptoms of dysphagia. With the aforementioned variables, there was a difference of $20 \%$ between the two groups. The ASD group also displayed obsessive eating patterns that were 13\% more severe than the TD group, which is statistically significant $(p=0.0226)$. The variable of atypical feeding behaviours showed the smallest difference in severity between the two groups, however, it remains significant $(\mathrm{p}=0.0001)$.

\section{Discussion}

The findings of this South African study support the previously established notion, in global studies, that children with ASD exhibit more feeding difficulties than peers without the disorder ${ }^{5,7}$. A novel finding that emerged was that participants in the group of children with ASD demonstrated swallowing difficulties not present in the TD group, a view which has received less attenton in past literature?. 
Food selectivity and preferences for children with ASD correlates with previous research findings indicating that food selectivity is more limiting for these children, than for typically developing peers ${ }^{19}$. Food selectivity can be due to extreme sensory modulation behaviours and sensory issues relating to smell, texture, colour and temperature of food $^{19}$. Additional causes may be found in the ASD population's inflexibility and repetitive behaviour patterns ${ }^{20}$. These sensory processing difficulties impacting negatively on feeding behaviour coincide with findings regarding children with ASD's preoccupation with sensory stimuli ${ }^{20}$.

Although the BAMBI identified dysphagia as a problem for children with ASD, the specific type and description of dysphagia cannot be determined by parental report. The same applies for the impact of inadequate oral motor skills on feeding.

Another variable investigated was obsessive eating habits. Frequent occurrence of obsessive eating behaviour was identified in children with ASD and may be related to the restrictive, repetitive or stereotypical patterns of behaviour that is characteristic of this population?

The findings regarding behavioural patterns during mealtimes such as crying or excessive screaming and disruptive behaviours are similar to findings from another research study ${ }^{7}$. This study found that children with ASD exhibit strong behavioural responses such as, pushing the plate or spoon away, and crying or turning their heads away when offered food they do not prefer or wish to consume $^{7}$. Furthermore, children with ASD often required specific utensils and food presentation. This corresponds with findings of individuals with ASD experiencing severe difficulties with the use of feeding utensils from childhood into adulthood ${ }^{22}$.

The comparative findings of this context-specific study indicated significant feeding and swallowing difficulties in children with ASD. The specific nature of the feeding and swallowing difficulties are linked to problems such as food selectivity and preferences, sensory processing difficulties, oral-motor difficulties and symptoms of dysphagia, as well as obsessive eating patterns and atypical feeding behaviours as is evident from previous global studies.

\section{Conclusion}

The findings of this study add to the body of existing research, globally as well as in the South African context on feeding and swallowing difficulties in young children with
ASD. This context specific study provides a better understanding of the severity and wide ranging feeding and swallowing problems displayed in young children with ASD. The findings also highlight the use of the BAM$\mathrm{BI}^{17}$ as an adjunct clinical tool for healthcare professionals assessing feeding behaviours assessment in the ASD population. However, cultural adaptation of the BAMBI for future use in African countries should be considered since the cultural demographics of the participants were varied. Some of the questions used could be rephrased to become more culturally relevant when presented to participants. The BAMBI was received surprisingly well considering the linguistically diverse participant group and the fact that the tool was not normed for the South African context. The participants understood the majority of the English questions. In addition future research on a rural sample may be of further benefit since there may be differences in how parents view children's feeding and swallowing abilities. These opinions may be based on the availability and access to services as well as information shared with parents by healthcare professionals in rural settings.

The findings showed a significant difference in the severity and range of feeding and swallowing difficulties in children with ASD compared to TD peers. These problems highlighted the multidimensional nature of feeding and swallowing difficulties in children with ASD, though TD peers also displayed some feeding difficulties such as picky eating. The findings may enable healthcare professionals in Africa to better understand aspects of feeding and swallowing to address in evidence-based individualized assessment and intervention.

Due to the multidimensional nature of the feeding and swallowing problems an interdisciplinary team are best suited to address the full spectrum of feeding and swallowing difficulties in the paediatric ASD population ${ }^{23}$. An interdisciplinary approach may contribute to decreased stress during mealtimes, safer swallowing and the development of functional skills required for oral feeding for all children with ASD. Interdisciplinary intervention may enable young children with ASD to engage more appropriately in mealtime activities of daily living. A further implication of the study was the need for parental education on the multidimensional aspects of feeding and swallowing difficulties young children with ASD experience that was emphasised by the findings.

African Health Sciences Vol 20 Issue 1, March, 2020 


\section{References}

1. Blumberg SJ, Bramlett MD, Kogan MD, Schieve LA, Jones JR, Lu MC. Changes in prevalence of parent-reported autism spectrum disorder in school-aged US children: 2007 to 2011-2012. US Department of Health and Human Services, Centers for Disease Control and Prevention, National Center for Health Statistics; 2013 Mar 20.

2. Burke A. Abnormal psychology: A South African perspective. Oxford University Press; 2009.

3. Iarocci G, McDonald J. Sensory integration and the perceptual experience of persons with autism. Journal of Autism and Developmental Disorders. 2006 Jan 1;36(1):77-90. 4. de Vries PJ. Thinking globally to meet local needs: autism spectrum disorders in Africa and other low-resource environments. Current Opinion in Neurology. 2016 Apr 1;29(2):130-6.

5. Kral TV, Souders MC, Tompkins VH, Remiker AM, Eriksen WT, Pinto-Martin JA. Child eating behaviors and caregiver feeding practices in children with autism spectrum disorders. Public Health Nursing. 2015 Sep 1;32(5):488-97.

6. Ledford JR, Gast DL. Feeding problems in children with autism spectrum disorders: A review. Focus on Autism and Other Developmental Disabilities. 2006 Aug;21(3):153-66. 7. Sharp WG, Jaquess DL, Lukens CT. Multi-method assessment of feeding problems among children with autism spectrum disorders. Research in Autism Spectrum Disorders. 2013 Jan 31;7(1):56-65.

8. Martins Y, Young RL, Robson DC. Feeding and eating behaviors in children with autism and typically developing children. Journal of Autism and Developmental Disorders.. 2008 Nov 1;38(10):1878-87.

9. Twachtman-Reilly J, Amaral SC, Zebrowski PP. Addressing feeding disorders in children on the autism spectrum in school-based settings: Physiological and behavioral issues. Language, Speech, and Hearing Services in Schools. 2008 Apr 1;39(2):261-72.

10. Johnson CR, Turner K, Stewart PA, Schmidt B, Shui A, Macklin E, Reynolds A, James J, Johnson SL, Courtney PM, Hyman SL. Relationships between feeding problems, behavioral characteristics and nutritional quality in children with ASD. Journal of Autism and Developmental Disorders. 2014 Sep 1;44(9):2175-84.

11. Smith AM, Roux S, Naidoo NR, Venter DJ. Food choices of tactile defensive children. Nutrition. 2005 Jan 31;21(1):14-9.
12. Laud RB, Girolami PA, Boscoe JH, Gulotta CS. Treatment outcomes for severe feeding problems in children with autism spectrum disorder. Behavior Modification. 2009 Sep;33(5):520-36.

13. Paik N. Dysphagia. Retrieved September 6, 2011, from http://emedicine.medscape.com/article/324096-overview.

14. De Vos AS, Delport CS, Fouché CB, Strydom H. Research at grass roots: A primer for the social science and human professions. Van Schaik Publishers; Pretoria, 2011.

15. Lord C, Risi S, DiLavore PS, Shulman C, Thurm A, Pickles A. Autism from 2 to 9 years of age. Archives of general Psychiatry. 2006 Jun 1;63(6):694-701.

16. Leedy PD, Ormrod JE. Practical research: Planning and design. Merril Publishing Company; Up Saddle River, New Jersey. 2012.

17. Lukens CT. Development and validation of an inventory to assess eating and mealtime behavior problems in children with autism (Doctoral dissertation, The Ohio State University); 2005.

18. Lukens CT, Linscheid TR. Development and validation of an inventory to assess mealtime behavior problems in children with autism. Journal of autism and developmental disorders. 2008 Feb 1;38(2):342-52.

19. Cermak SA, Curtin C, Bandini LG. Food selectivity and sensory sensitivity in children with autism spectrum disorders. Journal of the American Dietetic Association. 2010 Feb 28;110(2):238-46.

20. Matson JL, Fodstad JC. The treatment of food selectivity and other feeding problems in children with autism spectrum disorders. Research in Autism Spectrum Disorders. 2009 Jun 30;3(2):455-61.

21. Matson JL, Fodstad JC, Dempsey T. The relationship of children's feeding problems to core symptoms of autism and PDD-NOS. Research in Autism Spectrum Disorders. 2009 Sep 30;3(3):759-66.

22. Seiverling L, Williams K, Sturmey P. Assessment of feeding problems in children with autism spectrum disorders. Journal of Developmental and Physical Disabilities. 2010 Aug 1;22(4):401-13.

23. Lefton-Greif MA, Arvedson JC. Schoolchildren with dysphagia associated with medically complex conditions. Language, Speech, and Hearing Services in Schools. 2008 Apr 1;39(2):237-48. 